\title{
Multi-Objective Optimization using Evolutionary Computation Techniques
}

\author{
Rambabu CH \\ Electrical Department, \\ Sri Vasavi Engg College, \\ Tadepalligudem, W.G.DT, \\ A.P., INDIA
}

\author{
Dr.Y.P.Obulesh \\ Electrical Department, \\ L.B.R.College of Engineering, \\ Mylavaram, Krishna Dist, \\ A.P, INDIA
}

\author{
Dr.CH.Saibabu \\ Electrical Department, \\ JNTUK College of Engg., \\ Kakinada, E.G.Dt \\ A.P., INDIA
}

\begin{abstract}
In this paper an EP and PSO based optimization algorithms have been proposed for solving optimal power flow problems with multiple objective functions. These algorithms take into consideration all the equality and inequality constraints. The improvement in system performance is based on reduction in cost of power generation and active power loss. The proposed algorithms have been compared with the other methods reported in the literature. Simulation studies have been carried out for the optimal solutions of the IEEE 14-bus and IEEE 30-bus sy stems.
\end{abstract}

\section{Keywords}

EP, PSO, Active Power Loss

\section{INTRODUCTION}

The main objective of electric power utilities is to provide high quality reliable supply to the consumers at the lowest possible cost while operating to meet the limits and constraint imposed on the generating units. This formulates the well-known Economic Load Dispatch (ELD) problem for finding the optimal combination of the output power of all online generating units that minimizes the total fuel cost, while satisfying all constraints [1].

The Optimal Power Flow (OPF) is an important criterion in today's power system operation and control due to scarcity of energy resources, increasing power generation cost and ever growing demand for electric energy. As the size of the power system increases, load may be varying. The generators should share the total demand plus losses among themselves. The sharing should be based on the fuel cost of the total generation with respect to some security constraints. Generally, most of the approaches apply sensitivity analysis and gradient-based optimization algorithms by linearizing the objective function and system constraints around an operating point. Unfortunately, the problems of OPF are highly nonlinear and a multi model optimization problems, i.e. there exist more than one local optimum. Therefore, conventional optimization methods that make use of derivatives and gradients are, in general, not able to locate or identify the global optimum [7].

ELD is solved traditionally using mathematical programming based on optimization techniques such as lambda iteration, gradient method and so on. Economic load dispatch with piecewise linear cost functions is a highly heuristic, approximate and extremely fast form of economic dispatch. Complex constrained ELD is addressed by intelligent methods. Among these methods, some of them are genetic algorithm (GA) and, evolutionary programming (EP), dynamic programming
(DP), tabu search, hybrid EP, neural network (NN), adaptive Hopfield neural network (AHNN), particle swarm optimization (PSO) etc. For calculation simplicity, existing methods use second order fuel cost functions which involve approximation and constraints are handled separately, although sometimes valve-point effects are considered [13][15].

Intelligent methods are iterative techniques that can search not only local optimal solutions but also a global optimal solution depending on problem domain and execution time limit. They are general-purpose searching techniques based on principles inspired from the genetic and evolution mechanisms observed in natural sy stems and populations of living beings. These methods have the advantage of searching the solution space more thoroughly. The main difficulty is their sensitivity to the choice of parameters. Among intelligent methods, PSO is simple and promising. It requires less computation time and memory. It has also standard values for its parameters. In this, the Particle Swarm Optimization (PSO) is proposed as a methodology for economic load dispatch [2].

\section{OPF BY EVOLUTIONARY COMPUTATION TECHNIQUES}

\subsection{Evolutionary Programming (EP)}

Evolutionary Programming (EP) is an optimization technique based on the natural generation. It involves random number generation at the initialization process. The generated random numbers represent the parameters responsible for the optimization of the fitness value. In addition, EP also involves statistics, fitness calculation, mutation and the new generation will be bred by mode of selection. EP is a global optimization technique that starts with the population of randomly generated candidate solution and evolves a better solution over a number of generations or iterations. It is more suitable to effectively handle non-continuous and non-differentiable function. The main stage of this technique includes initialization, mutation, competition and selection [13].

\section{EP Algorithm}

i. An Initial population of $\mathrm{N}_{\mathrm{p}}$ parent vectors is considered as the trial solution

ii. From these parents off springs are created by mutation, hence $\mathrm{N}_{\mathrm{p}}$ off springs are obtained

iii. By combining the parents and off springs, $2 \mathrm{~N}_{\mathrm{p}}$ solutions are obtained

iv. Through competition and selection, first $\mathrm{N}_{\mathrm{p}}$ optimal solutions are selected 
v. The selected solutions are considered as parents for the next iteration

vi. After the required number of iterations, the best optimal solution is obtained.

\subsection{Particle Swarm Optimization}

PSO shares many similarities with evolutionary computation techniques such as Genetic Algorithms (GA). The system is initialized with a population of random solutions and searches for optima by updating generations. However, unlike GA, PSO has no evolution operators such as crossover and mutation [3]. Velocity of each agent can be modified by the following equation:

$$
\begin{gathered}
v_{i}^{k+1}=w v_{i}^{k}+c_{1} \text { rand }_{1} *\left(\text { pbest }_{i}-s_{i}^{k}\right)+c_{2} \text { rand }_{2} *\left(\text { gbest }_{i}^{k}\right) \\
w=w_{\max }-\left(\left(w_{\max }-w_{\min }\right) /\left(\text { iter }_{\max }\right)\right) * \text { iter }
\end{gathered}
$$

The current position (searching point in the solution space) can be modified by the following equation

$$
s_{i}^{k+1}=s_{i}^{k}+v_{i}^{k+1}
$$

\section{PSO Algorithm}

Step 1: Generation of initial condition of each agent. Initial searching points $\left(s_{i}^{0}\right)$ and velocities $\left(v_{i}^{0}\right)$ of each agent are usually generated randomly within the allowable range. The current searching point is set to pbest for each agent. The best evaluated value of pbest is set to gbest, and the agent number with the best value is stored.

Step 2: Evaluation of searching point of each agent. The objective function value is calculated for each agent. If the value is better than the current pbest of the agent, the pbest value is replaced by the current value. If the best value of pbest is better than the current gbest, gbest is replaced by the best value and the agent number with the best value is stored.

Step 3: Modification of each searching point. The current searching point of each agent is changed using eqns. (2.1), (2.2), and (2.3).

Step 4: Checking the exit condition. The current iteration number reaches the predetermined maximum iteration number, then exits. Otherwise, the process proceeds to step 2.

\section{MATHEMATICAL FORMULATION OF OPF PROBLEM}

The OPF problem is to optimize the steady state performance of a power system in terms of an objective function while satisfying several equality and inequality constraints. Mathematically, the OPF problem can be formulated as given [4][5]

$$
\text { Min } F(x, u)
$$

Subject to $g(x, u)=0$

$$
h(x, u) \leq 0
$$

Where $x$ is a vector of dependent variables consisting of slack bus power $P_{G_{1}}$, load bus voltages $V_{L}$, generator reactive power outputs $Q_{G}$, and the transmission line loadings $S_{l}$, Hence, $x$ can be expressed as given

$$
x^{T}=\left[P_{G_{1}}, V_{L_{1}} \ldots V_{L_{N L}}, Q_{G_{1}} \ldots Q_{G_{N G}}, S_{l} \ldots S_{l_{n l}}\right]
$$

Where $N L, N G$ and $n l$ are number of load buses, number of gen erators and number of transmission line respectively. $u$ is the vector of independent variables consisting of generator voltages $\mathrm{V}_{\mathrm{G}}$, generator real power outputs $P_{G}$ except at the slack bus $P_{G_{1}}$, transformer tap settings $T$, and shunt VAR compensations $Q_{C}$. Hence $u$ can be expressed as given

$$
u^{T}=\left[V_{G_{1}} \ldots V_{G_{N G}}, P_{G_{2}} \ldots P_{G_{N G}}, T_{1} \ldots T_{N T}, Q_{C_{1}} \ldots Q_{C_{N C}}\right]
$$

Where $N T$ and $N C$ are the number of the regulating transformers and shunt compensators, respectively. $F$ is the objective function to be minimized. $g$ is the equality constraints that represents typical load flow equations and $h$ is the system operating constraints

\section{Objectives}

The objectives considered for minimization are as follows. Objective Function 1: Fuel cost of generating units $\left(f_{1}\right)$

Objective Function 2: Active power loss $\left(f_{2}\right)$

Objective Function 3: Weighted multi objective function $\left(f_{3}\right)$ where

$$
\begin{aligned}
& f_{1}= \min \left(\sum_{i=1}^{N G}\left(a_{i} P_{G i}^{2}+b_{i} P_{G i}+C_{i}\right)\right. \\
& f_{2}=\min \left(\sum_{i=1}^{N L} G_{i j}\left(V_{i}^{2}+V_{j}^{2}-2 V_{i} V_{j} \cos \left(\delta_{i}-\delta_{j}\right)\right)\right. \\
& f_{3}=w_{1} * f_{1}+w_{2} * f_{2} \\
& \text { Here } w_{1}+w_{2}=1
\end{aligned}
$$

\section{Constraints}

The OPF problem has two categories of constraints:

Equality Constraints: These are the sets of nonlinear power flow equations that govern the power system, i.e.

$$
\begin{gathered}
P_{G i}-P_{D i}-\sum_{j=1}^{n}\left|V_{i}\right|\left|V_{j}\right|\left|Y_{i j}\right| \cos \left(\theta_{i j}-\delta_{i}+\delta_{j}\right)=0 \\
Q_{G i}-Q_{D i}+\sum_{j=1}^{n}\left|V_{i}\right|\left|V_{j} \| Y_{i j}\right| \sin \left(\theta_{i j}-\delta_{i}+\delta_{j}\right)=0
\end{gathered}
$$

where

$P_{G i}$ and $Q_{G i}$ are the real and reactive power outputs injected at bus- $i$ respectively, the load demand at the same bus is represented by $P_{D i}$ and $Q_{D i}$, and elements of the bus admittance matrix are represented by $\left|Y_{i j}\right|$ and $\theta_{i j}$.

Inequality Constraints: These are the set of constraints that represent the system operational and security limits like the bounds on the following:

1) Generators real and reactive power outputs

$$
\begin{aligned}
& P_{G i}^{\min } \leq P_{G i} \leq P_{G i}^{\max }, i=1, \ldots, N_{G} \\
& Q_{G i}^{\min } \leq Q_{G i} \leq Q_{G i}^{\max }, i=1, \ldots, N_{G}
\end{aligned}
$$

2) Voltage magnitudes at each bus in the network

$$
V_{i}^{\min } \leq V_{i} \leq V_{i}^{\max }, i=1, \ldots, N L
$$

3) transformer tap settings

$$
T_{i}^{\min } \leq T_{i} \leq T_{i}^{\max }, i=1, \ldots, N T
$$

4) Reactive power injections due to capacitor banks

$$
Q_{C i}^{\min } \leq Q_{C i} \leq Q_{C i}^{\max }, i=1, \ldots, C S
$$

5) Transmission lines loading

$$
S_{i} \leq S_{i}^{\max }, i=1, \ldots, n l
$$

6) Voltage stability index 


$$
L j_{i} \leq L j_{i}^{\max }, i=1, \ldots, N L
$$

Handling of Constraints: There are different ways to handle constraints in evolutionary computation optimization algorithms. In this thesis, the constraints are incorporated into fitness function by means of penalty function method, which is a penalty factor multiplied with the square of the violated value of variable is added to the objective function and any infeasible solution obtained is rejected.

To handle the inequality constraints of state variables including load bus voltage magnitudes and output variables with real power generation output at slack bus, reactive power generation output, and line loading, the extended objective function can be defined as:

$$
O F=\sum_{i=1}^{N} F_{i}\left(P_{G i}\right)+K_{p} h\left(P_{G 1}\right)+K_{q} \sum_{i=1}^{N} h\left(Q_{G i}\right)+K_{v} \sum_{i=1}^{N L} h\left(\left|V_{i}\right|\right)+K_{s} \sum_{i=1}^{N L} h\left(\left|S_{i}\right|\right)
$$

where

$K_{p}, K_{q}, K_{v}, K_{s}$ are penalty constants for the real power generation at slack bus, the reactive power generation of all generator buses or PV buses and slack bus, the voltage magnitude of all load buses or PQ buses, and line or transformer loading, respectively. $h\left(P_{G 1}\right), h\left(Q_{G i}\right), h\left(\left|V_{i}\right|\right), h\left(\left|S_{i}\right|\right)$ are the penalty function of the real power generation at slack bus, the reactive power generation of all $\mathrm{PV}$ buses and slack bus, the voltage magnitudes of all PQ buses, and line or transformer loading, respectively. NL is the number of PQ buses. The penalty function can be defined as:

$$
\begin{gathered}
h(x)=\left(x-x_{\max }\right)^{2}, \text { if } x>x_{\max } \\
=\left(x_{\min }-x\right)^{2}, \text { if } x<x_{\min } \\
=0 \quad, \text { if } x_{\min } \leq x \leq x_{\max }
\end{gathered}
$$

where $h(x)$ is the penalty function of variable $x, x^{\max }$ and $x^{\text {min }}$ are the upper limit and lower limit of variable $x$, respectively.

In this section i describe the dataset and how it is used to detect intrusions. I first examine what type of data was present in the dataset, what intrusion types were represented and what features were extracted.

\section{COMPUTATIONAL PROCEDURE}

Step 1: Input the system data for load flow analy sis

Step 2: Run the power flow

Step 3: At the generation Gen $=0$; set the simulation parameters of EP/PSO parameters and randomly initialize $\mathrm{k}$ individuals within respective limits and save them in the archive.

Step 4: For each individual in the archive, run power flow to determine load bus voltages, angles, load bus voltage stability indices, generator reactive power outputs and calculate line power flows.

Step 5: Evaluate the penalty functions

Step 6: Evaluate the objective function values and the corresponding fitness values for each individual.

Step 7: Find the generation local best xlocal and global best xglobal and store them.

Step 8: Increase the generation counter Gen $=\mathrm{Gen}+1$.
Step 9: Apply the EP/PSO operators to generate new $\mathrm{k}$ individuals

Step 10: For each new individual in the archive, run power flow to determine load bus voltages, angles, load bus voltage stability indices, generator reactive power outputs and calculate line power flows.

Step 11: Evaluate the penalty functions

Step 12: Evaluate the objective function values and the corresponding fitness values for each new individual.

Step 13: Apply the selection operator of EP/PSO and update the individuals.

Step 14: Update the generation local best xlocal and global best xglobal and store them.

Step 15: If one of stopping criterion have not been met, repeat steps 4-15. Else go to step 16

Step 16: Print the results

There are two stopping criterion for the optimization algorithm. The algorithm can be stopped if the maximum number of generations is reached $\left(\mathrm{Gen}=\mathrm{Gen}_{\max }\right)$ or there is no solution improvement over a specified number of generations. The first criterion is used in this paper.

\section{SIMULATION RESULTS}

The proposed EP and PSO algorithms for solving optimal power flow problems are tested on standard IEEE $14 \&$ IEEE 30-bus test systems. The EP and PSO parameters used for the simulation are summarized in Table 1

Table 1 Optimal parameter settings for EP and PSO

\begin{tabular}{|l|c|c|}
\hline \multicolumn{1}{|c|}{ Parameter } & EP & PSO \\
\hline Population size & 20 & 20 \\
Number of iterations & 250 & 150 \\
Cognitive constant, c1 & - & 2 \\
Social constant, c2 & - & 2 \\
Inertia weight, W & - & $0.3-0.95$ \\
\hline
\end{tabular}

\subsection{IEEE 14-bus system results}

\begin{tabular}{|c|c|c|c|c|}
\hline & $\begin{array}{c}\text { Convergen } \\
\text { ce of } \\
\text { objective } \\
\text { function-1 }\end{array}$ & $\begin{array}{c}\text { Convergen } \\
\text { ce of } \\
\text { objective } \\
\text { function-2 }\end{array}$ & $\begin{array}{l}\text { Convergen } \\
\text { ce of } \\
\text { objective } \\
\text { function- } \\
3 \text { (Cost) }\end{array}$ & $\begin{array}{c}\text { Convergenc } \\
\text { e of } \\
\text { objective } \\
\text { function- } \\
\text { 3(Loss) }\end{array}$ \\
\hline $\begin{array}{l}\text { EP- } \\
\text { OPF }\end{array}$ & $=4$ & tist) & 1: & |cis \\
\hline $\begin{array}{c}\text { PSO } \\
- \\
\text { OPF }\end{array}$ & _. & $=$ & $1:$ & 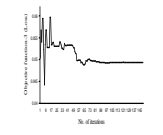 \\
\hline
\end{tabular}

Figures 1 shows the convergence characteristics of the three objective functions. It can be observed that the EP converge to lower values than PSO during initial evolutions and the PSO converge to a minimum value than EP after 20 iterations.

Fig 1 Convergence of multiple objective functions by EP and PSO 
Table 2 Optimal settings of control variables

\begin{tabular}{|c|c|c|c|c|c|c|}
\hline \multirow{2}{*}{$\begin{array}{c}\text { Control } \\
\text { variables }\end{array}$} & \multicolumn{2}{|l|}{ Objective function-1 } & \multicolumn{2}{|l|}{ Objective function-2 } & \multicolumn{2}{|c|}{ Objective function- } \\
& \multicolumn{2}{|c|}{} & \multicolumn{2}{|c|}{3} \\
\cline { 2 - 7 } & EP & PSO & EP & PSO & EP & PSO \\
\hline $\mathrm{P}_{\mathrm{G} 1}$ & 1.1242 & 1.1279 & 0.2485 & 0.6138 & 1.1191 & 1.1278 \\
$\mathrm{P}_{\mathrm{G} 2}$ & 0.7000 & 0.7000 & 0.7000 & 0.3889 & 0.7000 & 0.7000 \\
$\mathrm{P}_{\mathrm{G} 3}$ & 0.2783 & 0.2749 & 0.8000 & 0.8000 & 0.2728 & 0.2748 \\
$\mathrm{P}_{\mathrm{G} 4}$ & 0.2605 & 0.2613 & 0.5424 & 0.5019 & 0.2746 & 0.2627 \\
$\mathrm{P}_{\mathrm{G} 5}$ & 0.2778 & 0.2746 & 0.3163 & 0.3049 & 0.2734 & 0.2739 \\
\hline $\mathrm{Q}_{\mathrm{G} 1}$ & 0.0100 & -0.0929 & 0.0741 & 0.1796 & -0.0789 & -0.0936 \\
$\mathrm{Q}_{\mathrm{G} 2}$ & 0.1108 & 0.0534 & 0.0506 & -0.1906 & 0.1838 & 0.0574 \\
$\mathrm{Q}_{\mathrm{G} 3}$ & 0.1760 & 0.0373 & 0.1786 & -0.0342 & 0.1688 & 0.0370 \\
$\mathrm{Q}_{\mathrm{G} 4}$ & 0.1283 & 0.0924 & 0.0044 & 0.1807 & 0.0322 & 0.1177 \\
$\mathrm{Q}_{\mathrm{G} 5}$ & 0.0995 & 0.1459 & 0.0505 & 0.0628 & 0.1177 & 0.1782 \\
\hline $\mathrm{V}_{1}$ & 1.0700 & 1.0700 & 1.0700 & 1.0700 & 1.0700 & 1.0715 \\
$\mathrm{~V}_{2}$ & 1.0567 & 1.0621 & 1.0644 & 1.0541 & 1.0609 & 1.0621 \\
$\mathrm{~V}_{3}$ & 1.0275 & 1.0389 & 1.0541 & 1.0425 & 1.0321 & 1.0387 \\
$\mathrm{~V}_{4}$ & 1.0137 & 1.0598 & 1.0491 & 1.0309 & 1.0564 & 1.0520 \\
$\mathrm{~V}_{5}$ & 1.0480 & 1.0688 & 1.0326 & 1.0387 & 1.0571 & 1.0784 \\
\hline $\mathrm{T}_{1}$ & 0.9543 & 1.0322 & 1.0260 & 1.0064 & 1.0331 & 1.0118 \\
$\mathrm{~T}_{2}$ & 1.0879 & 0.9000 & 0.9665 & 0.9360 & 0.9017 & 0.9201 \\
$\mathrm{~T}_{3}$ & 1.0157 & 0.9922 & 0.9669 & 1.0473 & 0.9617 & 1.0004 \\
\hline
\end{tabular}

\begin{tabular}{|c|c|c|c|c|c|c|}
\hline $\mathrm{Q}_{\text {sh1 }}$ & 0.0521 & 0.0260 & 0.0016 & 0.0183 & 0.0369 & 0.0500 \\
$\mathrm{Q}_{\text {sh2 }}$ & 0.0975 & 0.0500 & 0.0105 & 0.0098 & 0.1000 & 0.0500 \\
$\mathrm{Q}_{\text {sh3 }}$ & 0.0191 & 0.0351 & 0.0389 & 0.0348 & 0.0658 & 0.0218 \\
$\mathrm{Q}_{\text {sh4 }}$ & 0 & 0.0500 & 0.0824 & 0.0178 & 0.0364 & 0.0208 \\
$\mathrm{Q}_{\text {sh5 }}$ & 0.0306 & 0.0500 & 0.0787 & 0.0399 & 0.0551 & 0 \\
\hline Cost & 840.114 & 839.0662 & 1105.4 & 1072.1 & 839.70 & 839.27 \\
(\$/hr) & & & & & & \\
\hline Loss & 0.0509 & 0.0488 & 0.0583 & 0.0194 & 0.0499 & 0.0493 \\
p.u.MW & & & & & & \\
\hline CPU & 63.0150 & 35.5470 & 60.9060 & 39.7190 & 62.969 & 41.469 \\
Ti me & & & & & & \\
\hline
\end{tabular}

The above table presents the optimal settings of the controlvariables with the three objective functions. From the Table 2, it was found that all the state variables satisfy their lower and upper limits.

It can be observed that the PSO algorithm is able to reduce the cost of generation less than that of the cost of generation obtained by the EP method. It is also evident from the results that particle swarm optimization technique outperforms in achieving minimum of the specified objective under different network contingencies when compared with evolutionary programming method.

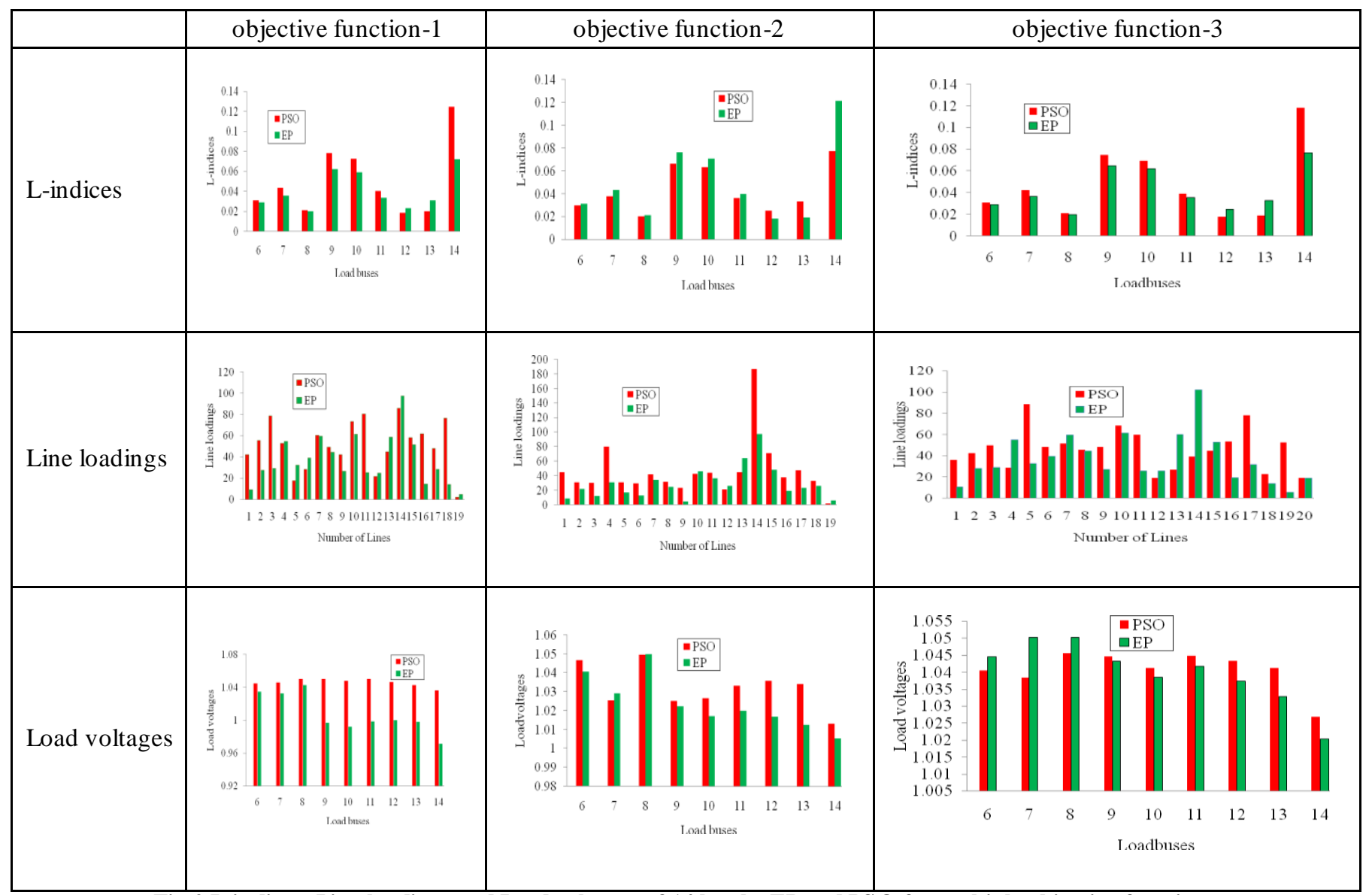

Fig 2 L-indices, Line loadings and Load voltages of 14 bus by EP and PSO for multiple objective functions

Figures 2 shows the percentage line loadings, load bus voltages and voltage stability indices after the optimization by EP and PSO methods with the three objective functions.

\subsection{IEEE 30-bus system results}

The proposed PSO algorithm was applied to find the optimal scheduling of the power system for the base case loading condition to minimize specified objective functions. Generator active-power outputs, generator terminal voltages, transformer tap settings and shunt reactive power compensating elements were taken as control variables. The control variables are represented as floating point numbers in the population. The upper and lower voltage limits of load buses were taken as 1.06 and 0.95 respectively. 


\begin{tabular}{|c|c|c|c|c|}
\hline & $\begin{array}{l}\text { Convergen } \\
\text { ce of } \\
\text { objective } \\
\text { function-1 }\end{array}$ & $\begin{array}{l}\text { Convergen } \\
\text { ce of } \\
\text { objective } \\
\text { function- } 2\end{array}$ & $\begin{array}{l}\text { Convergenc } \\
\text { e of } \\
\text { objective } \\
\text { function- } \\
\text { 3(Cost) }\end{array}$ & $\begin{array}{l}\text { Convergen } \\
\text { ce of } \\
\text { objective } \\
\text { function- } \\
\text { 3(Loss) }\end{array}$ \\
\hline $\begin{array}{l}\text { EP- } \\
\text { OPF }\end{array}$ & 证 & $=$ & & $=0$ \\
\hline $\begin{array}{c}\text { PSO } \\
- \\
\text { OPF }\end{array}$ & $=$ & $\mathrm{L}_{2}$ & " & $=$ \\
\hline
\end{tabular}

Fig 3 Convergence of multiple objective functions by EP and PSO

Figure 3 shows the convergence characteristics of the three objective functions. It can be observed that the EP converge to lower values than PSO during initial evolutions and the PSO converge to a minimum value than EP after 20 iterations.

Table 3 Optimal settings of control variables

\begin{tabular}{|c|c|c|c|c|c|c|}
\hline $\begin{array}{c}\text { Contro } \\
1 \\
\text { variabl } \\
\text { es }\end{array}$ & \multicolumn{2}{|c|}{$\begin{array}{c}\text { Objective } \\
\text { function-1 }\end{array}$} & \multicolumn{2}{c|}{$\begin{array}{c}\text { Objective } \\
\text { function-2 }\end{array}$} & \multicolumn{2}{c|}{$\begin{array}{c}\text { Objective } \\
\text { funct ion-3 }\end{array}$} \\
\cline { 2 - 7 } & EP & PSO & EP & PSO & EP & PSO \\
\hline $\mathrm{P}_{\mathrm{Gl}}$ & 1.7814 & 1.7616 & 0.5304 & 0.9421 & 1.7778 & 1.7618 \\
$\mathrm{P}_{\mathrm{G} 2}$ & 0.4990 & 0.4885 & 0.7940 & 0.6868 & 0.4985 & 0.4884 \\
$\mathrm{P}_{\mathrm{G} 3}$ & 0.1961 & 0.2207 & 0.3500 & 0.2480 & 0.2008 & 0.2212 \\
$\mathrm{P}_{\mathrm{G} 4}$ & 0.1200 & 0.1217 & 0.3000 & 0.1768 & 0.1167 & 0.1220 \\
$\mathrm{P}_{\mathrm{G}}$ & 0.2242 & 0.2150 & 0.5000 & 0.4870 & 0.2277 & 0.2151 \\
$\mathrm{P}_{\mathrm{G} 6}$ & 0.1206 & 0.1200 & 0.4000 & 0.3405 & 0.1200 & 0.1200 \\
\hline $\mathrm{Q}_{\mathrm{G} 1}$ & -0.196 & -0.162 & -0.186 & -0.056 & -0.143 & -0.200 \\
$\mathrm{Q}_{\mathrm{G} 2}$ & 0.1451 & 0.1268 & 0.1183 & -0.0017 & 0.1859 & 0.0698 \\
$\mathrm{Q}_{\mathrm{G} 3}$ & 0.3189 & -0.012 & 0.3264 & 0.1036 & 0.2465 & 0.0956 \\
$\mathrm{Q}_{\mathrm{G} 4}$ & 0.1496 & 0.2631 & 0.0022 & 0.1485 & 0.0308 & 0.2648 \\
\hline
\end{tabular}

\begin{tabular}{|c|c|c|c|c|c|c|}
\hline $\mathrm{Q}_{\mathrm{G} 5}$ & 0.4744 & 0.0988 & 0.3885 & 0.0538 & 0.4489 & 0.0889 \\
$\mathrm{Q}_{\mathrm{G} 6}$ & 0.1218 & 0.2056 & 0.0912 & 0.2138 & 0.2000 & 0.4472 \\
\hline $\mathrm{V}_{1}$ & 1.0500 & 1.0500 & 1.0500 & 1.0500 & 1.0500 & 1.0500 \\
$\mathrm{~V}_{2}$ & 1.0364 & 1.0379 & 1.0500 & 1.0418 & 1.0345 & 1.0385 \\
$\mathrm{~V}_{3}$ & 1.0284 & 1.0189 & 1.0444 & 1.0282 & 1.0175 & 1.0196 \\
$\mathrm{~V}_{4}$ & 1.0649 & 1.1000 & 1.0330 & 1.0538 & 1.0375 & 1.1000 \\
$\mathrm{~V}_{5}$ & 1.0148 & 1.0109 & 1.0349 & 1.0209 & 1.0080 & 1.0121 \\
$\mathrm{~V}_{6}$ & 1.0634 & 1.0768 & 1.0571 & 1.0432 & 1.0577 & 1.1000 \\
\hline $\mathrm{T}_{1}$ & 1.0331 & 1.0049 & 1.0115 & 1.0000 & 0.9769 & 0.9956 \\
$\mathrm{~T}_{2}$ & 0.9327 & 0.9591 & 0.9544 & 0.9964 & 1.0058 & 0.9819 \\
$\mathrm{~T}_{3}$ & 0.9891 & 1.0064 & 1.0041 & 1.0473 & 1.0240 & 1.1000 \\
$\mathrm{~T}_{4}$ & 0.9611 & 0.9592 & 0.9842 & 0.9616 & 0.9812 & 0.9755 \\
\hline $\mathrm{Q}_{\text {sh1 }}$ & 0.0054 & 0.0282 & 0.0154 & 0.0166 & 0.0342 & 0 \\
$\mathrm{Q}_{\text {sh2 }}$ & 0.0057 & 0.0443 & 0.0237 & 0.0239 & 0.0238 & 0.0231 \\
$\mathrm{Q}_{\text {sh3 }}$ & 0.0127 & 0.0365 & 0.0605 & 0.0259 & 0.0709 & 0.0495 \\
$\mathrm{Q}_{\text {sh4 }}$ & 0.0641 & 0.0414 & 0.0560 & 0.0321 & 0.0415 & 0.0447 \\
$\mathrm{Q}_{\text {sh5 }}$ & 0.1000 & 0.0389 & 0.0461 & 0.0168 & 0.0491 & 0.0336 \\
$\mathrm{Q}_{\text {sh6 }}$ & 0.0581 & 0.0415 & 0.0913 & 0.0378 & 0.0544 & 0.0500 \\
$\mathrm{Q}_{\text {sh7 }}$ & 0.0507 & 0.0339 & 0.0410 & 0.0205 & 0.0419 & 0.0234 \\
$\mathrm{Q}_{\text {sh8 }}$ & 0.0495 & 0.0500 & 0.0243 & 0.0269 & 0.0200 & 0.0500 \\
$\mathrm{Q}_{\text {sh9 }}$ & 0.0275 & 0.0326 & 0.0283 & 0.0257 & 0.0761 & 0.0500 \\
\hline Cost & 806.3633 & 801.9525 & 968.6317 & 899.1088 & 806.619 & 802.268 \\
(\$hr) & & & & & & \\
\hline Loss & 0.1703 & 0.0936 & 0.0494 & 0.0472 & 0.1075 & 0.0944 \\
p.u.MW) & & & & & & \\
\hline CPU & 145 & 92.172 & 134.0320 & 129.6410 & 120.263 & 90.9330 \\
Time & & & & & & \\
\hline Tabl & & & & &
\end{tabular}

Table 3 presents the optimal settings of the control-variables with the three objective functions. From the Table 3, it was found that all the state variables satisfy their lower and upper limits.

From the Table 5.3, it can be observed that the PSO algorithm is able to reduce the cost of generation less than that of the cost of generation obtained by the EP method. It is also evident from the results that particle swarm optimization technique outperforms in achieving minimum of the specified objective under different network contingencies when compared with evolutionary programming method.

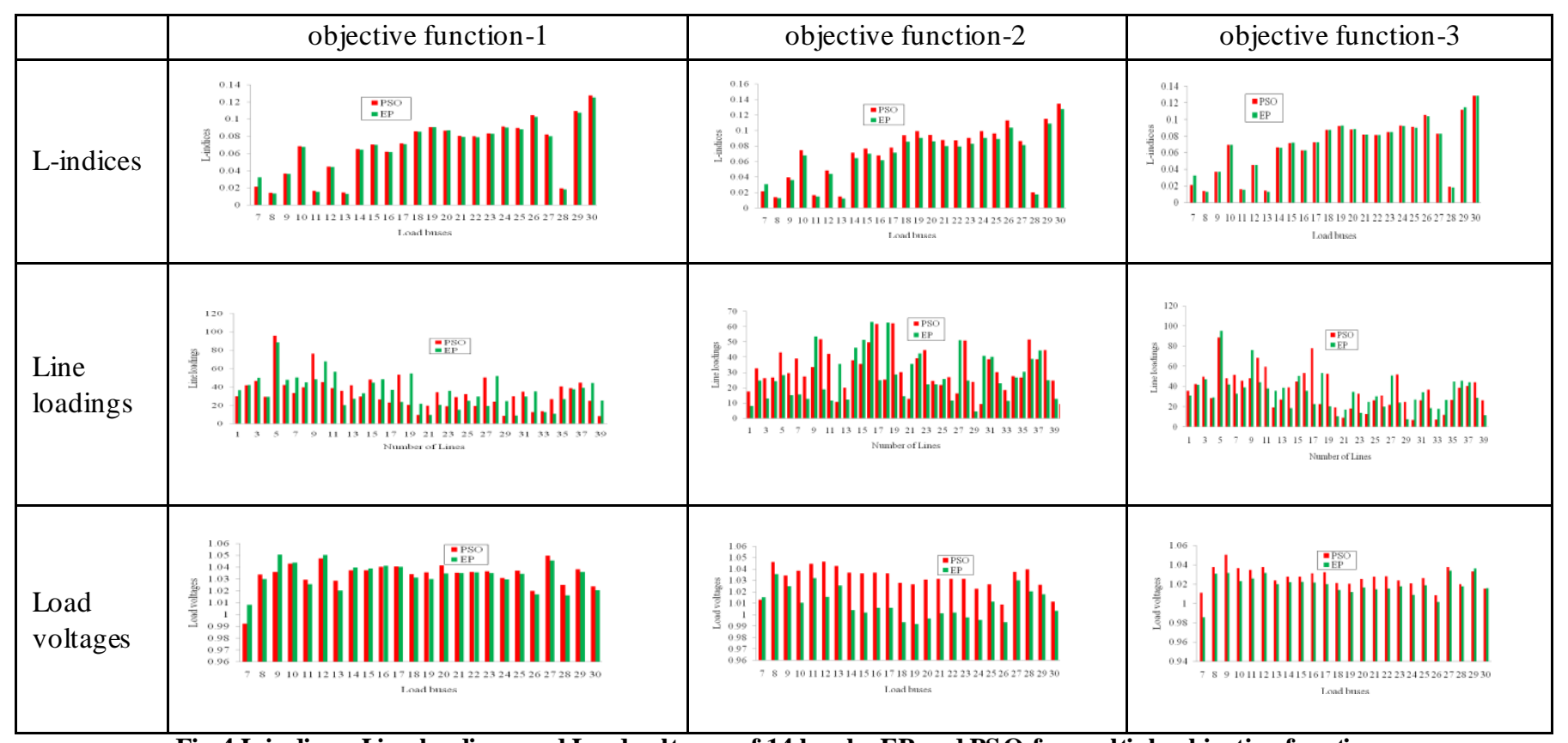

Fig 4 L-indices, Line loadings and Load voltages of 14 bus by EP and PSO for multiple objective functions 
Figure 4 shows the percentage line loadings, load bus voltages and voltage stability indices after the optimization by EP and PSO methods with the three objective functions.

The comparison of fuel cost of the proposed methods with those of the methods reported in the literature for IEEE 30-bus sy stem is given in Table 4. It can be seen from the Table 5.4 that the PSO algorithm gives less cost of generation compared with the cost of generation obtained with other methods.

Table 4 Comparison of fuel costs

\begin{tabular}{|c|c|}
\hline Method & Fuel Cost (\$/hr) \\
\hline EP [13] & 802.9070 \\
\hline TS [13] & 802.5020 \\
\hline TS/SA [13] & 802.7880 \\
\hline ITS [13] & 804.5560 \\
\hline IEP [13] & 802.4650 \\
\hline SADE_ALM [15] & 802.4040 \\
\hline OPFPSO [14] & 800.4100 \\
\hline MDE-OPF [16] & 802.3760 \\
\hline Genetic Algorithm [17] & 803.05 \\
\hline Gradient method [18] & 802.43 \\
\hline PSO (proposed) & 801.9525 \\
\hline
\end{tabular}

Here an IEEE-30 bus system is considered. Evolutionary programming (EP) method has been applied on the IEEE-30 bus system. Here we have considered three objective functions. Objective function 1 is the cost objective function. Objective function 2 is the loss objective function. Objective function 3 is the multi objective function i.e. both cost and losses are taken as objectives. The fitness function is taken as the reciprocal of the objective function.

\section{CONCLUSION}

An EP and PSO based optimization algorithms have been proposed for solving optimal power flow problems with different objective functions. These algorithms take into consideration all the equality and inequality constraints. The improvement in system performance is based on reduction in cost of power generation and active power loss. The proposed algorithms have been compared with the other methods reported in the literature. Simulation studies have been carried out for the optimal solutions of the IEEE 14-bus and IEEE 30-bus systems. It was observed that the results obtained by the proposed algorithms can be implemented in real life power systems for operation and analy sis.

Based on the overall observations from the results obtained on various IEEE test systems, it can be concluded that the proposed methods for optimal solutions are suitable for implementing in modern power system operation.

\section{REFERENCES}

[1] Kennedy J, Eberhart R. "Particle swarm optimization" Proceedings of IEEE International Conference on Neural Networks (ICNN'95) Perth, Australia: IEEE Press; 1995. Vol. IV. p. 1942-1948.

[2] Shi Y, Eberhart R. "A modified particle swarm optimizer" Proceedings of IEEE International Conference on
Evolutionary Computation (ICEC'98). Anchorage: IEEE Press; 1998. p. 69-73.

[3] Shi Y, Eberhart R. "Parameter selection in particle swarm optimization" Proceedings of the 1998 Annual Conference on Evolutionary Programming. San Diego: MIT Press; 1998.

[4] Fukuyama Y. et al. "A particle swarm optimization for reactive power and voltage control considering voltage security assessment". IEEE Trans Power Systems 2000; 15(4):1232-1239.

[5] Naka S, Genji T, Yura T, Fukuy ama Y. "A hybrid particle swarm optimization for distribution state estimation" IEEE Trans Power Systems 2003; 18(1):60-68.

[6] IEEE Special Publication $90^{\mathrm{TH}}$ 0358-2PWR, "Voltage Stability of Power Sy stems: Concepts, Analytical Tools and Industry Experience", The IEEE Working Group on Voltage Stability, 1990.

[7] A J Wood and B F Wollenberg, "Power generation operation and control", John Wiley and Sons Inc.Singapore, 1984.

[8] Brian Stott, Ongun Alsac, and Alcir J. Monticelli, "Security analysis and optimization", Proc. of IEEE, Vol.75, No.12, December 1987, pp.1623-1644.

[9] Parker, C.J., I. F Morrison, and D. Sutanto, “Application of an optimization method for determining the reactive margin from voltage collapse in reactive power planning", IEEE Trans. on Power Systems, Vol.11, No. 3, August 1996, pp. 1473-1481.

[10] Venikov, V.A., V.A Stroev, V.I. Idelchick, and V.I. Tarasov, "Estimation of electric power system steady state stability in load flow calculations", IEEE Trans. on PAS, Vol.PAS-94, No.3, May/June 1975, pp.1034-1040.

[11] P.A. Lof,G. Andersson, D. Hill, "Voltage dependent reactive power limits for voltage stability studies", IEEE Trans.on power systems, Vol. 10, No. 1, Feb. 1995, pp. 220-228.

[12] P Kessel and H Glavitsch, "Estimating the voltage stability of a power system", IEEE Trans. on PD, Vol.1, No.3, pp.346-354, 1986.

[13] W. Ongsakul and T. Tantimaporn, "Optimal power flow by improved evolutionary programming", Electric Power Components and Systems, 2006, 34:pp.79-95,.

[14] Abido MA. "Optimal power flow using particle swarm optimization," Electric Power Energy Syst 2002; 24(7): pp.563-71.

[15] Peerapol Jirapong and Weerakorn Ongsakul "Optimal placement of multi type FACTS devices for total transfer capability enhancement using hybrid evolutionary algorithm", Electric power componenets and systems, 01 September 2007, 35:pp.981-1005.

[16] Ramasubramanian Jayashree and Mohammed Abdullah Khan "A unified optimization approach for the enhancement of available transfer capability and congestion management using unified power flow controller", Serbian 
journal of electrical engineering, Vol.5, No.2, November 2008, pp.305-324.

[17] D.Devaraj and B.Yegnanarayana, "Genetic AlgorithmBased Optimal Power Flow for Security Enhancement", IEE Proceedings on Generation, Transmission and Distribution 2005, 152(6), pp 899-905.

[18] X.P.Zhang, S.G.Petoussis and K.R.Godfrey "Nonlinear interior point optimal power flow method based on a current mismatch formulation", IEE Proc.-Gener. Transm. Distrb. Vol.152, No.6, January 2005, pp.795-805.

\section{AUTHORS PROFILE}

Mr. Ch.Rambabu received the Bachelor of Engineering degree in Electrical \& Electronics En gineering from Madras University, in 2000 and Master's degree from JNTU Anantapur in 2005. He is a research student of JNTU Kakinada. Currently, he is an Associate Professor at Sri Vasavi Engineering College. His interests are in power system control and FACTS.
Dr. Y.P.Obulesh received his B.E degree in Electrical Engineering from Andhra University, Visakhapatnam in 1996. M.Tech., degree from IIT, Kharagpur, in 1998. He received his Ph.D. degree from Jawaharlal Nehru Technological University Hyderabad, in 2006. Currently he is working as a Professor and head of Dept. of EEE at LBRCEC, Mylavaram. He has published several National and International Journals and Conferences. His area of interest is the simulation and design of power electronics systems, DSP controllers, fuzzy logic and neural network application to power electronics and drives.

Dr. Ch. Sai Babu received the B.E from Andhra University (Electrical \& Electronics Engineering), M.Tech in Electrical Machines and Industrial Drives from REC, Warangal and Ph.D. in Reliability Studies of HVDC Converters from JNTU, Hyderabad. Currently he is working as a Professor in Dept. of EEE in JNTUCEK, Kakinada. He has published several National and International Journals and Conferences. His area of interest is Power Electronics and Drives, Power System Reliability, HVDC Converter Reliability, Optimization of Electrical Systems and Real Time Energy Management. 